Website: http://journal.umy.ac.id/index.php/mrs

DOI: $10.18196 /$ jmmr.6122

\title{
Kualitas Pelayanan Kepuasan Pasien Rumah Sakit: Kasus Pada Pasien Rawat Jalan
}

\author{
Solichah Supartiningsih* \\ *Penulis Korespondensi: solichah.supartiningsih@gmail.com \\ *Rumah Sakit Sarila Husada Sragen, Indonesia

\begin{tabular}{l}
\hline $\boldsymbol{I} \boldsymbol{N} \boldsymbol{D} \boldsymbol{E} \boldsymbol{X} \boldsymbol{I N} \boldsymbol{G}$ \\
\hline Keywords: \\
Tangible; \\
Reliability; \\
Responsiveness; \\
Assurance; \\
Empathy
\end{tabular}

A B S T R A C T
The purpose of this study was to determine the effect of service quality dimensions in terms of
physical appearance, reliability, responsiveness, assurance, and empathy for hospital patient
satisfaction Sarila Husada Sragen. This study uses a test approach the relationship between
variables with quantitative approach. Samples are patients who use the services of Sarila Husada
Hospital of Sragen. Test the relationship between variables was performed using multiple regression
test. This study found that tangbel and assurance effect on customer satisfaction Sarila Husada
hospital patients Sragen. \\ Kata kunci: \\ Tampilan Fisik; \\ Tujuan Penelitian ini adalah Untuk mengetahui pengaruh kualitas pelayanan ditinjau dari dimensi \\ Tampilan fisik, keandalan, daya tanggap, jaminan, dan empati terhadap kepuasan pasien rumah sakit \\ Sarila Husada Sragen. Penelitian ini menggunakan pendekatan uji hubungan antar variabel dengan \\ pendekatan kuantitatif. Sampel penelitian adalah pasien yang menggunakan jasa Rumah Sakit Sarila \\ Husada Sragen. Uji hubungan antar variabel dilakukan dengan teknik uji regresi berganda. Penelitian \\ ini menemukan bahwa tangbel dan assurance berpengaruh terhadap kepuasan Pelanggan pasien \\ rumah sakit Sarila Husada Sragen.
}

(C) 2017 JMMR. All rights reserved

$\overline{\text { Article history: Received } 25}$ Jul 2016; Revised 19 Okt 2016; Accepted 25 Nov 2016

\section{PENDAHULUAN}

Rumah sakit adalah suatu organisasi yang dilakukan oleh tenaga medis profesional yang terorganisir baik dari sarana prasarana kedokteran yang permanen, pelayanan kedokteran, asuhan keperawatan yang berkesinambungan, diagnosis serta pengobatan penyakit yang diderita oleh pasien. ${ }^{-}$Era globalisasi tidak bisa dihindari sehingga diperlukan sikap yang arif dan bijaksana. Walaupun dalam strategi World Trade Organization (WTO) pada tahun 2010 Indonesia baru akan membuka dokter asing diperbolehkan praktek di Indonesia, namun Association of Southeast Asian Nations (ASEAN) sepakat tahun 2008 akan membuka untuk tenaga kesehatan, untuk itu semua yang bekerja dalam bidang kesehatan harus bekerja secara proposional dan selalu bertolak untuk kepentingan pasien (http://m.depkes.go.id/).

Industri jasa pelayanan masyarakat juga tidak terlepas dari persaingan antar pelakunya, yaitu rumah sakit. Berbagai rumah sakit yang ada berupaya memperoleh kepercayaan masyarakat dengan mengemukakan pelayanan yang efisien dan berkualitas. Rumah sakit umum daerah merupakan salah satu bagian dari industri jasa pelayanan yang ada, sayangnya citra dari rumah sakit daerah di mata masyarakat kurang baik dibandingkan dengan pelayanan kesehatan rumah sakit swasta.

Rumah sakit mempunyai berbagai macam jenis pelayanan kesehatan yang dapat diunggulkan untuk mempertahankan loyalitas pasien. Salah satu jenis pelayanan kesehatan yang ada di rumah sakit yaitu pelayanan rawat jalan. Pelayanan rawat jalan dewasa ini menjadi perhatian utama manajemen rumah sakit, karena jumlah pasien rawat jalan yang lebih banyak dibandingkan dengan perawatan yang lain. Pelayanan rawat jalan menjadi pangsa pasar yang menjanjikan dan dapat mendatangkan keuntungan financial bagi rumah sakit. Persaingan yang semakin ketat akhirakhir ini menuntut sebuah lembaga penyedia jasa untuk selalu memanjakan pelanggan dengan memberikan pelayanan terbaik. Para pelanggan mencari 
produk berupa barang atau jasa dari perusahaan yang dapat memberikan pelayanan yang terbaik kepadanya.?

RS Sarila Husada Sragen merupakan salah satu rumah sakit yang menyediakan pelayanan kesehatan bagi masyarakat di wilayah Sragen dan sekitarnya. RS Sarila Husada Sragen berusaha untuk terus menerus meningkatkan kualitas pelayanan tanpa mengabaikan fungsi sosial sebagai instansi kesehatan. RS Sarila Husada Sragen juga terus mengembangkan dan melengkapi sarana prasarana kesehatan sesuai dengan visi RS Sarila Husada Sragen agar menjadi rumah sakit pilihan masyarakat Sragen sekitarnya dalam mencari dan mendapatkan pelayanan kesehatan. Seiring dengan berjalannya waktu dimana Rumah Sakit Sarila Husada Sragen menghadapi isu-isu strategis, yaitu belum optimalnya pelayanan kesehatan, masih adanya keluhan pasien terhadap pelayanan yang ada, kurangnya sarana dan prasarana pelayanan kesehatan, persiapan pengelolaan menjadi Badan Layanan Umum (BLU), persaingan diantara rumah sakit di sekitarnya. Sehingga keadaan tersebut berakibat adanya kompetisi yang sangat sengit diantara rumah sakit yang ada.

Dalam pola interaksi sosial, persepsi pasien sangat berperan dalam menggambarkan tingkat kepuasan pasien terhadap pelayanan rumah sakit. Berdasarkan persepsi ini timbul kesan pasien terhadap rumah sakit, yang selanjutnya dapat disebut sebagai kualitas pelayanan rumah sakit. Kesan yang didapat dibangun atas persepsi masing-masing individu yang berelasi.

Dalam menganali permasalahan tersebut diatas, maka peneliti mencoba melihat dari sisi penerima pelayanan atau pelanggan dalam mengevaluasi kesenjangan antara harapan dan persepsi terhadap kualitas jasa pelayanan kesehatan yang diberikan oleh instalasi rawat jalan Rumah Sakit Sarila Husada Sragen. Kesenjangan merupakan ketidaksesuaian antara pelayanan yang dipersepsikan (perceived service) dan pelayanan yang diharapkan (expected service). Kesenjangan diakibatkan oleh ketidaktahuan manajemen atas pelayanan yang diharapkan oleh pelanggan. Oleh karena itu untuk mengukur kesenjangan tersebut, secara teoritis model yang dapat digunakan adalah model SERVQUAL yang terdiri dari dimensi bukti fisik, keandalan, daya tanggap, jaminan, empati, yang dikembangkan oleh Para Suraman et al. ${ }^{3}$ Dengan menggunakan model ini, RS sebagai penyedia jasa layanan tidak hanya bisa menilai kualitas keseluruhan jasanya seperti dipersepsikan pelanggan namun juga bisa mengidentifikasi dimensi-dimensi kunci dan aspek-aspek dalam setiap dimensi tersebut yang membutuhkan penyempurnaan kualitas.

Mutu pelayanan yang baik tidak hanya diukur dari kemewahan fasilitas, kelengkapan teknologi dan penampilan fisik akan tetapi dari sikap dan perilaku karyawan harus mencerminkan profesionalisme dan mempunyai komitmen tinggi. Pada pelaksanaannya, survei kepuasan pasien dilakukan untuk memperbaiki lingkungan rumah sakit, fasilitas pasien, dan fasilitas dalam konteks konsumerisme. Efektivitas diukur berdasarkan umpan balik pasien untuk meningkatkan ketrampilan penyedia layanan kesehatan dan praktekpraktek yang masih menjadi kontroversi. Tujuan dari studi ini adalah untuk menilai pendapat staf klinis atas hasil survei kepuasan pasien rawat inap dan kegunaannya dalam proses quality improvement, untuk melihat dan mengkaji sejauh mana hasil survei kepuasan pasien ini bermanfaat dalam proses quality improvement, dilakukan survei terhadap provider pelayanan kesehatan terhadap hasil survei kepuasan pasien tersebut. Tujuan survei ini adalah untuk menilai pendapat staf klinis terhadap hasil survei kepuasan pasien rawat inap dan penggunaannya dalam proses quality improvement, khususnya umpan balik di bangsal terkait.

Kepuasan pasien merupakan cerminan kualitas pelayanan kesehatan yang mereka terima.- Mutu pelayanan kesehatan merjuk pada tingkat kesempurnaan pelayanan kesehatan dalam menimbulkan rasa puas pada diri setiap pasien. Makin sempurna kepuasan tersebut, makin baik pula mutu pelayanan kesehatan. Namun demikian, kualitas pelayanan yang relatif baik belum tentu bisa memuaskan pasien. Pada umumnya pasien tidak dapat menilai kompetensi teknis, sehingga mereka menilai mutu layanan dari karakteristik nonteknis atau hubungan interpersonal dan kenyamanan pelayanan. $-\frac{5}{-}$ Menurut hasil penelitian ditemukan adanya perbedaan dimensi, yaitu: 1) Bagi pemakai jasa pelayanan kesehatan, mutu pelayanan kesehatan lebih terkait pada dimensi ketanggapan petugas memenuhi kebutuhan pasien, kelancaran komunikasi petugas dengan pasien, keprihatinan serta keramahtamahan petugas dalam melayani pasien dan atau kesembuhan penyakit yang sedang diderita pasien. 2) Bagi penyelenggara pelayanan kesehatan, 
mutu pelayanan kesehatan lebih terkait pada dimensi kesesuaian pelayanan yang diselenggarakan dengan perkembangan ilmu dan teknologi mutakhir dan atau otonomi profesi dalam menyelenggarakan pelayanan kesehatan sesuai dengan kebutuhan pasien. 3) Bagi penyandang dana pelayanan kesehatan, mutu pelayanan kesehatan lebih terkait pada dimensi efisiensi pemakaian sumber dana, kewajaran pembiayaan kesehatan dan atau kemampuan pelayanan kesehatan mengurangi kerugian penyandang dana pelayanan kesehatan. ${ }^{4}$

Perbedaan dimensi itulah yang sering menimbulkan kekecewaan pasien, meskipun petugas sudah menerapkan standar operasional prosedur dengan baik. Oleh karena itu aspek kepuasan pelanggan perlu mendapatkan perhatian serius, karena meski bersifat subyektif tetapi menentukan preferensi selanjutnya dalam memilih sarana pelayanan kesehatan.

Sebagai penyedia jasa yang memberikan berbagai macam pelayanan bagi konsumen, maka kepuasan konsumen merupakan tujuan utama yang harus dipenuhi perusahaan. Kepuasan konsumen adalah tingkat perasaan seseorang setelah membandingkan kinerja/hasil yang dirasakannya dengan harapannya. ${ }^{-}$Jadi, untuk meningkatkan kepuasan pasiennya khususnya pasien Jamkesmas pihak Rumah Sakit, peranan dokter dan perawat baik medis dan non medis sangat menentukan persepsi pasien terhadap pelayanan yang diberikan.

Menurut data Rumah Sakit Sarila Husada 20132015, pada tahun 2013 pelayanan pada poli umum (rawat jalan) menjadi layanan yang paling banyak dibandingkan poli yang lain. Tahun 2014 terjadi penurunan poli umum tetapi terjadi peningkatan pada poli IGD dan tahun 2015 terjadi penurunan pasien umum dan lebih merujuk ke poli bagian paling tinggi terdapat pada pasien IGD. Hal tersebut menunjukkan bahwa pasien kurang puas pada rumah sakit tersebut.

Dari latar belakang masalah tersebut, maka penulis tertarik mengadakan penelitian terkait kualitas kelayanan terhadap kepuasan pasien Rumah Sakit Sarila Husada Sragen pada Pasien Rawat Jalan. Penelitian ini akan berfokus pada beberapa hal, yakni: 1) Bagaimana pengaruh kualitas pelayanan ditinjau dari dimensi tampilan terhadap kepuasan pasien rumah sakit Sarila Husada Sragen pada pasien Rawat Jalan?; 2) Bagaimana pengaruh kualitas pelayanan ditinjau dari dimensi keandalan terhadap kepuasan pasien rumah sakit Sarila Husada Sragen pada pasien Rawat Jalan?; 3) Bagaimana pengaruh kualitas pelayanan ditinjau dari dimensi daya tanggap terhadap kepuasan pasien rumah sakit Sarila Husada Sragen pada pasien Rawat Jalan?; 4) Bagaimana pengaruh kualitas pelayanan ditinjau dari dimensi jaminan terhadap kepuasan pasien rumah sakit Sarila Husada Sragen pada pasien Rawat Jalan?; dan 5) Bagaimana pengaruh kualitas pelayanan ditinjau dari dimensi empati terhadap kepuasan pasien rumah sakit Sarila Husada Sragen pada pasien Rawat Jalan?.

Hasil penelitian ini diharapkan dapat memberikan kontribusi teoritis berupa pengembangan konsep kualitas pelayanan, khususnya pada lembaga public yakni rumah sakit. Secara praktis dapat menjadi bahan pertimbangan dalam penyusunan kebijakan terkait pelayanan rumah sakit, khususnya untuk kasus jasa rawat jalan.

\section{METODE PENELITIAN}

Jenis penelitian ini adalah penelitian asosiatif yaitu penelitian yang bertujuan untuk mengetahui hubungan antara dua variabel atau lebih. ${ }^{7}$ Penelitian ini bertujuan untuk menganalisis pengaruh kualitas pelayanan terhadap kepuasan pasien Rumah Sakit Sarila Husada Sragen pada pasien rawat jalan.

Subyek penelitian ini adalah 100 pasien rawat jalan di Rumah Sakit Sarila Husada Sragen. Obyek penelitian ini adalah kualitas pelayanan di Rumah Sakit Sarila Husada Sragen mencakup aspek Bukti fisik (Tangible), Keandalan (Reliability), Daya tanggap (Responsiveness), Jaminan (Assurance), dan Empati (Emphaty). Teknik analisis data menggunakan analisis deskriptif dan analisis regresi berganda.

\section{HASIL DAN PEMBAHASAN}

Kualitas dapat diartikan bahwa kualitas hidup kerja harus merupakan suatu pola pikir (mindset), yang dapat menterjemahkan tuntutan dan kebutuhan pasar konsumen dalam suatu proses manajemen dan proses produksi barang atau jasa terus menerus tanpa hentinya sehingga memenuhi persepsi kualitas pasar konsumen tersebut. ${ }^{?}$ 
Analisis kesahihan dilakukan dengan bantuan komputer dengan program 15.0 for window yang bertujuan untuk mengetahui apakah setiap butir item pernyataan yang dinilai atau dievaluasi oleh responden dapat dinyatakan valid atau tidak. Pengujian hasilnya dengan cara membandingkan koefisien $\alpha$ ( $\mathrm{r}$ hitung) dengan nilai kritis ( $\mathrm{r}$ tabel) yang hasilnya dapat dilaporkan.

Tabel 1. Reliabilitas

\begin{tabular}{cccc}
\hline Variabel & Nilai Alpha & Ketentuan nilai Alpha & Keterangan \\
\hline Produk & 0,878 & 0,5 & Reliabel \\
Harga & 0,736 & 0,5 & Reliabel \\
Faktor emosional & 0,938 & 0,5 & Reliabel \\
Kemudahan & 0,698 & 0,5 & Reliabel \\
Nyata & 0,935 & 0,5 & Reliabel \\
Reliabilitas (keandalan) & 0,833 & 0,5 & Reliabel \\
Responsivitas (daya tanggap) & 0,751 & 0,5 & Reliabel \\
Kepastian/ jaminan & 0,765 & 0,5 & Reliabel
\end{tabular}

Sumber : Data Primer Yang Diolah Tahun 2016

Seluruh butir pernyataan untuk tiap variabel dinyatakan reliabel yang artinya jika instrument tersebut digunakan beberapa kali untuk mengukur objek yang sama akan menghasilkan data yang sama pula.

Sebelum dilakukan uji hubungan antar variabel, terlebih dahulu dilakukan uji validitas dan reliabilitas instrument kuesioner penelitian. Analisis kesahihan validitas dilakukan dengan bantuan komputer program SPSS 15.00 for windows yang bertujuan untuk mengetahui apakah setiap butir pernyataan dinilai atau dievaluasi dapat dinyatakan valid atau tidak. Simpulan valid tidaknya dari item pertanyaan dilakukan dengan membandingkan koefisien $r_{x y}$ dengan nilai kritis $\left(r_{\text {tabe }}\right)$.

Tabel 1. Karakteristik Responden berdasarkan

Umur

\begin{tabular}{ccc}
\hline Umur (tahun) & Frequency & $\mathbf{\%}$ \\
\hline $20-30$ tahun & 5 & 5 \\
$31-40$ tahun & 59 & 59 \\
$41-50$ tahun & 36 & 36 \\
Total & 100 & 100 \\
\hline
\end{tabular}

\section{Hasil Uji Analisis Validitas dan Reliabilitas}

Dari hasil analisis ditemukan bahwa nilai $r$ statsitik lebih besar dari pada $r$ tabel. Dengan demikian dapat dikatakan item pertanyaan kuesioner untuk semua variabel valid. Selanjutnya, analisis kesahihan reliablitas dilakukan dengan melihat hasil analisis nilai cronbach alpha. Dari hasil analisis dengan SPSS, ditemukan nilai cronbach alpha lebih dari 05. Dengan demikian, dapat dikatakan bahwa item pertanyaan pada kuesioner untuk semua variabel telah reliabel.

\section{Hasil Analisis Regresi linier Berganda}

Analisis dalam penelitian ini adalah analisis Regresi Linier Berganda. Analisis ini digunakan untuk mengetahui variabel tangibel $\left(\mathrm{X}_{1}\right)$, Reabilitas $\left(\mathrm{X}_{2}\right)$, Responsives $\left(\mathrm{X}_{3}\right)$, Asurance $\left(\mathrm{X}_{4}\right)$, Emphaty $\left(\mathrm{X}_{5}\right)$ terhadap kepuasan Pelanggan pasien rumah sakit Sarila Husada Sragen pada pasien Rawat Jalan (Y). Adapun bentuk persamaan regresinya adalah $\mathrm{Y}=\mathrm{b}_{0}+\mathrm{b}_{1} \mathrm{X}_{1}+$ $\mathrm{b}_{2} \mathrm{X}_{2}+\mathrm{b}_{3} \mathrm{X}_{3}+\mathrm{b}_{4} \mathrm{x}_{4}+\mathrm{b}_{5} \mathrm{x}_{5}$ Berikut ini table hasil regresi berganda metode OLS (Ordinary Least Square) (lihat Tabel 2). 


\section{Hasil Pengujian $\mathbf{R}^{2}$ (Koefisien Determinasi)}

$\mathrm{R}^{2}$ (Koefisien Determinasi) ini digunakan untuk mengenal seberapa besar kemampuan variabel independen dalam menjelaskan secara komprehensif terhadap variabel dependen. Nilai $R^{2}$ (Koefisien Determinasi) mempunya range antar 0-1. Semakin besar $\mathrm{R}^{2}$ mengindifikasikan semakin besar kemampuan variabel independen dalam memjelaskan variabel dependen.

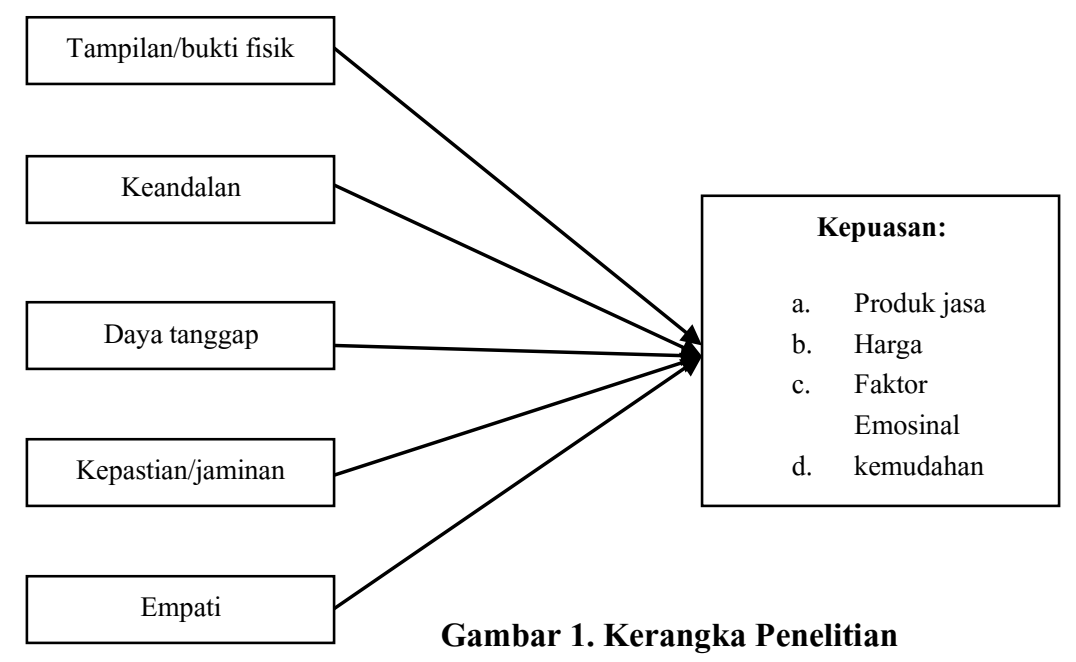

Tabel 2. Rangkuman Hasil Uji Hubungan antar Variabel dengan Regresi Berganda

\begin{tabular}{cccc}
\hline Variabel & Beta & Sig (P-Vaue) & Simpulan \\
\hline X1_tangible & -.310 & .088 & Tidak Berpengaruh \\
X2_reliability & .655 & $.004^{*}$ & Berpengaruh \\
X3_responsiveness & .058 & .795 & Tidak Berpengaruh \\
X4_assurance & .264 & $.022^{*}$ & Berpengaruh \\
X5_emphaty & -.091 & .709 & Tidak Berpengaruh \\
\hline
\end{tabular}

R2 (Koefisien Determinasi) ini digunakan untuk mengenal seberapa besar kemampuan variabel independen dalam menjelaskan secara komprehensif terhadap variabel dependen. Nilai R2 (Koefisien Determinasi) mempunya range antar 0-1. Semakin besar R2 mengindifikasikan semakin besar kemampuan variabel independen dalam memjelaskan variabel dependen.

Hasil dari regresi dengan metode OLS diperoleh $\mathrm{R}^{2}$ (Koefisien Determinasi atau R Square) sebesar 0,377 artinya variabel dependen (Y) dalam model yaitu kepuasan pasien rumah sakit Sarila Husada Sragen pada pasien Rawat Jalan (Y) dijelaskan oleh variabel independen yaitu variabel tangible $\left(\mathrm{X}_{1}\right)$, reability $\left(\mathrm{X}_{2}\right)$, responsive $\left(\mathrm{X}_{3}\right)$, Asurance $\left(\mathrm{X}_{4}\right)$, Emphaty $\left(\mathrm{X}_{5}\right)$ terhadap kepuasan pasien rumah sakit Sarila Husada Sragen pada pasien Rawat Jalan (Y) sebesar 37,7\%, sedangkan sisanya sebesar $62,3 \%$ dijelaskan oleh variabel lain diluar model.

\section{Pembahasan}

Hasil analisis menunjukan bahwa variabel bukti fisik (tangible) tidak mempunyai pengaruh positif terhadap kepuasan pasien rumah sakit Sarila Husada Sragen pada pasien Rawat Jalan. Hal ini dapat diartikan jika perlengkapan sarana dan prasarana meningkat maka kepuasan pasien rumah sakit Sarila Husada Sragen pada pasien Rawat Jalan belum tentu akan meningkat pula.

Hasil analisis menunjukkan bahwa variabel keandalan (reliability) mempunyai pengaruh positif dan signifikan terhadap kepuasan pasien rumah sakit Sarila Husada Sragen pada pasien Rawat Jalan. Hal ini 
dapat diartikan jika kemampuan dalam memberikan pelayanan dengan segera dan memuaskan serta sesuai dengan apa yang dijanjikan meningkat maka kepuasan pasien rumah sakit Sarila Husada Sragen pada pasien Rawat Jalan akan meningkat pula.

Hasil analisis menunjukan bahwa variabel daya tanggap (responsiveness) tidak mempunyai pengaruh positif dan tidak signifikan terhadap kepuasan pasien rumah sakit Sarila Husada Sragen pada pasien Rawat Jalan. Hal ini dapat diartikan jika kemampuan para karyawan untuk membantu pelanggan dan memberikan pelayanan dengan tanggap belum tentu dapat meningkatkan kepuasan pasien rumah sakit Sarila Husada Sragen pada pasien Rawat Jalan.

Hasil analisis menunjukkan bahwa variabel jaminan (assurance) mempunyai pengaruh positif dan signifikan terhadap kepuasan pasien rumah sakit Sarila Husada Sragen pada pasien Rawat Jalan. Hal ini dapat diartikan jika sifat yang dapat dipercaya yang dimiliki karyawan meningkat maka kepuasan pasien rumah sakit Sarila Husada Sragen pada pasien Rawat Jalan akan meningkat pula.

Hasil analisis menunjukkan bahwa variabel empati (emphaty) tidak mempunyai pengaruh positif dan signifikan terhadap kepuasan pasien rumah sakit Sarila Husada Sragen pada pasien Rawat Jalan. Hal ini dapat diartikan jika kemudahan untuk memberikan keterangan dan perhatian kepada pasien dengan baik belum tentu meningkat maka kepuasan pasien rumah sakit Sarila Husada Sragen pada pasien Rawat Jalan mempunyai kecenderungan menurun.

\section{SIMPULAN}

Setelah penulis melakukan hasil penelitian dan pembahasan maka penulis dapat mengambil kesimpulan: Variabel bukti fisik (tangible) mempunyai pengaruh negatif dan tidak signifikan terhadap kepuasan pasien rumah sakit Sarila Husada Sragen pada pasien Rawat Jalan. Hipotesis ditolak. Variabel keandalan (reliability) mempunyai pengaruh positif dan signifikan terhadap kepuasan pasien rumah sakit Sarila Husada Sragen pada pasien Rawat Jalan. Hipotesis diterima. Variabel daya tanggap (responsiveness) mempunyai pengaruh positif dan tidak signifikan terhadap kepuasan pasien rumah sakit Sarila Husada Sragen pada pasien Rawat Jalan. Hipotesis diterima. Variabel jaminan (assurance) mempunyai pengaruh positif dan signifikan terhadap kepuasan pasien rumah sakit Sarila Husada Sragen pada pasien Rawat Jalan. Hipotesis diterima. Variabel empati (emphaty) mempunyai pengaruh negatif dan tidak signifikan terhadap kepuasan pasien rumah sakit Sarila Husada Sragen pada pasien Rawat Jalan. Hipotesis ditolak.

Dari hasil analisis menunjukan bahwa variabel bebas yang paling rendah memberikan pengaruh pada kepuasan pelanggan adalah tampilan/bukti fisik dan kepastian/jaminan. Agar kepuasan pelanggan semakin tinggi terhadap rumah sakit Sarila Husada Sragen pada pasien Rawat Jalan hendaknya direktur rumah sakit meningkatkan tampilan/bukti fisik dengan cara selalu melengkapi sarana dan prasarana rumah sakit. Agar kepuasan pelanggan semakin tinggi terhadap rumah sakit Sarila Husada Sragen pada pasien Rawat Jalan hendaknya Direktur rumah sakit meningkatkan ruang tunggu dan ruang rawat jalan dibuat serapi mungkin terutama supaya pasien merasa nyaman.

\section{DAFTAR PUSTAKA}

1. Armstrong, Gary dan Philip Kotler. 1996. Principles of Marketing. 7th edition. Prentice Hall International Inc, New Jersey.

2. Sofyan Assauri. 2003. Manajemen Pemasaran Jasa, Jilid 1, Jakarta, PT. Gramedia Pustaka Utama.

3. Parasuraman, et al. 1998. Service quality : $A$ multiple item scale for measuring consumer perception of service quality

4. Azwar,Azrul., 1994. Pengantar Administrasi Kesehatan, Edisi ketiga, Ciputat,. Tangerang : Binarupa Aksara

5. Blank, W.E. 1982. Handbook for Developing Competency-Based Training Programs. Englewood Cliffs, New Jersey : Prentice-Hall.

6. Kotler dan Keller, 2007. Manajemen Pemasaran, Edisi 12, Jilid 1, PT.Indeks,. Jakarta. Hardiansyah. 2011. Kualitas Pelayanan Publik. Yogyakarta: Gava Media.

7. Nova, Rahadi Fitra., 2010. Pengaruh Kualitas Pelayanan Terhadap Kepuasan Pasien Rawat Inap Pada Rumah Sakit Pku Muhammadiyah Surakarta. Surakarta: Fakultas Ekonomi 
Universitas Sebelas Maret Surakarta.

https://core.ac.uk/download/pdf/12348901.pdf 